\title{
Crop Yield Response and Community Resilience to Climate Change in the Bamenda Highlands
}

\author{
Innocent Ndoh Mbue ${ }^{1, ~ *}$, Bitondo Dieudonne ${ }^{1}$, Roland Balgah Azibo ${ }^{2}$ \\ ${ }^{1}$ Department of Industrial Quality, Hygiene, Safety \& Environment, University of Douala, Douala, Cameroon \\ ${ }^{2}$ College of Technology, University of Bamenda, Bambili, Cameroon
}

Email address:

dndoh2009@gmail.com (I. N. Mbue)

${ }^{*}$ Corresponding author

\section{To cite this article:}

Innocent Ndoh Mbue, Bitondo Dieudonne, Roland Balgah Azibo. Crop Yield Response and Community Resilience to Climate Change in the Bamenda Highlands. American Journal of Biological and Environmental Statistics. Vol. 5, No. 3, 2019, pp. 31-41.

doi: 10.11648/j.ajbes.20190503.11

Received: June 24, 2019; Accepted: August 4, 2019; Published: August 14, 2019

\begin{abstract}
Climate change seems to be the most phytotoxic of all global changes. One of its most subtle impacts on plants development is on their reproductive processes. There has been very little work directed towards agrobiodiversity, and especially subsistence and cash crops in highland ecosystems. An understanding of the effects of climate change on the yield of such crops could contribute to the sustainable management of such ecosystems to avoid degradation and subsequent increases in poverty and hunger. This cross-sectional study assesses the trends and effects of climate change on the reproductive processes of plant species within rainfed agricultural systems in the Bamenda Highlands of Cameroon, together with community resilience. Twenty-four-year climatic data $(1991$ - 2015) and crop yield statistic over the same period constituted our secondary data sources. Primary data from field observations and focus group interviews with some 140 farmers complemented our database. Multiple regression analysis was used to test if rainfall and temperature significantly predicted crop yield. Community resilience was captured using ten indicators of social-ecological resilience in four domains. The results showed that, for the subsistence crops, the main effect of temperature on yield was significant, F $(2,23)=7.91$, MSE $=23.20$, $\mathrm{p}<.01$, as was the main effect of precipitation, $\mathrm{F}(2,23)=12.70, \mathrm{MSE}=23.20, \mathrm{p}<.01$. Declining yields have led to high prices of food items in the market, undermining food security. On the contrary, the two predictors of crop yield explained only $16.4 \%$ of the variance in cash crop yield $\left(\mathrm{R}^{2}=.164, \mathrm{~F}(2,21)=2.065, \mathrm{p}=.152\right)$. Neither rainfall $(\beta=.296, \mathrm{p}=.236)$ nor temperature ( $B=.-177.013, p=.233$ ) significantly predicted cash crop yield (tea) yield, suggesting that decline in production could be as a result of estraneous variables such as the political environment and inadequate agricultural inputs. Consensus scores and trends for the indicators of social-ecological resilience ranged from low to medium, indicating a rather weak capacity of communities to cope with external stresses and disturbances. Cash-crop intensification, a driver of biodiversity loss elsewhere, did not negatively affect native tree richness within parcels. The result suggests a need to open up procedures and practices of participation and inclusion in order to accommodate pluralism, contestation and incommensurable perspectives and knowledge systems. Joining efforts to build community resilience, specifically by increasing livelihood diversity, local ecological knowledge, and social network connectivity, may help conservation agencies conserve the rapidly declining agrobiodiversity in the region.
\end{abstract}

Keywords: Bamenda Highlands, Community Resilience, Rainfall, Temperature, Local Ecological Knowledge

\section{Introduction}

No other form of physical change has had as widespread detrimental effect on the growth and reproductive capacity of crops as climate change. Manifesting itself through temperature increases, rainfall reduction, increase in pests and disease incidences, droughts and floods, etc., climate change (including climate variability) already affects physical processes in many parts of the world, leading to changes in temperature and rainfall patterns, in wind direction and increased intensity and frequency of extreme 
events like droughts, floods and cyclones [1], and affecting agricultural yields in many parts of the world [2]. Worldwide, climate change intensifies some of the hazards affecting social systems and weakens resilience in facing uncertainty and disasters [3]. Likely temperature increases will continue to change precipitation patterns with impacts on infrastructure, environment and health [4], decrease agricultural production [5], land productivity [6] and livelihood of rural communities [7]. As we transition to the new Sustainable Development Agenda (2015-2030) the fight against eradicating hunger continues as about 795 million people globally still remain undernourished, 780 million of whom live in developing countries [8]. In regions like Sub-Saharan Africa, where the agricultural sector provides employment to $60 \%$ of the population and adds $30 \%$ to the Gross Domestic Product [9], the interactions between climate change trends and farming systems vulnerability may put increasing pressure on the livelihoods of the poor.

The recent decades ushered in considerable international humanitarian focus on reducing hunger for all people, regardless of nationality, ethnicity, age, income, and geographic location. The concept of resilience emerged as a key concept for policy and program development [10], possibly and controversially replacing sustainability as the ultimate objective. The concept of community resilience [11] has gained increasing prominence in science and policy circles. The concept as an essential step toward reducing disaster risk and being better prepared to withstand and adapt to a broad array of natural and human-induced disasters [12]. The resilience concept proposes a vision of sustainable development paired with a set of skills to cope with anthropogenic and natural vulnerability including temperature variation and rising input price [13]. It has been argued that an approach that relies on governing resilience in order to meet ongoing challenges is most effective [14] when it is used in the context of increasing urbanization [15]. However, as a standalone approach, this cannot be a holistic panacea to declining livelihoods and food insecurity.

In addition to the concept of community resilience, crop yield models have been proposed as a central tool in informing agro-industry and policymakers about the risks and potential of adaptation strategies to counter climate change, as well as directing plant scientists and breeders towards the required traits in improved varieties and cropping systems' management practices. To deal with these unpredictable risks, traditional agroforestry systems, where crops are grown within shifting mosaics of forests and fallows, have been promoted and practiced worldwide for millennia. These technologies have been capable of producing food while maintaining high levels of native biodiversity and ecosystem function [16]. Because they tend to focus on locally adapted crops, can be biodiverse at multiple ecological scales, and require low inputs, agroforests are also thought to be more resilient to climate change than other agricultural systems [17]. As such, there are growing calls from governmental and nongovernmental agencies worldwide to promote these systems [18].

To predict future impacts on crop yields, the Decision Support System for Agrotechnology Transfer (DSSAT), CERES-Maize (Crop Environment Resource Synthesis), CERES-Wheat, SWAP (soil-water-atmosphere-plant), and InFoCrop [19] have been widely used to analyze crop yield-climate sensitivity under different climate scenarios. To quantify the uncertainties in crop yield prediction, the ensemble approach [20] has received growing attention in impact assessments. Using this approach, the uncertainties from climate projections and crop models can be analyzed and quantified through series of parameter estimations within the models [21]. However, crop model inter-comparison studies have identified large uncertainties and biases [22], and unfortunately they do not often incorporate current knowledge of plant responses to growth under high atmospheric $\mathrm{CO}_{2}$ concentrations [23].

These scientific findings, and many others have made enormous breakthrough in this field, however, they appear to be complex and might not be easily extended to smallholder farmers who dominate the agricultural sector in sub-Sahara Africa when compared with state-of-the-art reference system. We strongly believe that, more attention to employing iterative processes that involve scenario-based planning such as the integration of technical and local knowledge could increase local capacity and better address challenges associated with climate change uncertainties. Adaptive capacities strengthened through collective action can compel formalization or strengthening of structures that can have an impact at higher levels. The purpose of this research was therefore to combine time series crop yield and climate data with information on farmer's ability to anticipate, absorb, accommodate, or recover from climate change in a timely and efficient manner, for improved adaptation to climate change risks taking the Bamenda Highlands of Cameroon as an example. In contrast with the past studies which examined the effect of precipitation and temperature on crop yields, here we work with the communities in order to integrate technical and local knowledge, thereby increasing the chances that the research will result in relevant design, adoption of the findings, and increased local capacity. The concept of resilient adaptation can serve as a guiding principle for planning adaptations which account for uncertainties in future climate change. Specifically the research aims to answer the following key questions:

1. What are current and future trends in temperature and precipitation in the Bamenda Highlands of Cameroon?

2. What are the relationships between the trends in (1) and crop yield over the past decades?

3. Are there some crops that are tolerant to climate change related stresses in the region?

4. How have the communities in this region been able to cope with threats resulting from socioeconomic and physical changes? 


\section{Material and Methods}

\subsection{Study Design}

Because we wanted the study to be intuitively clear, and to allow for the examination of a large number of variables at one specific point in time in the region/sample population, a cross sectional design was adopted. Though the design cannot be used to infer causality because a temporal sequence cannot be established, nevertheless, it allowed us to generate descriptive statistics regarding the outcome burden in the population, or to determine background exposure rates.

\subsection{Study Area/Setting}

Also known as the Bamenda Grassfields, the Bamenda Highlands is a region of Cameroon characterised by high relief, cool temperatures, heavy rainfall and savanna vegetation. It lies between latitudes $5^{\circ} 40^{\prime}$ and $7^{\circ}$ to the North of the equator, and between longitudes $9^{\circ} 45$ and $11^{\circ} 10^{\prime}$ to the East of the Meridian. It is a living landscape cared for by the traditional custodians for millennia, bordered to the south-west by the South-West region, to the south-East by the West Region, to the North East by the Adamawa Region, and to the West and North by the Federal Republic of Nigeria (Figure 1).

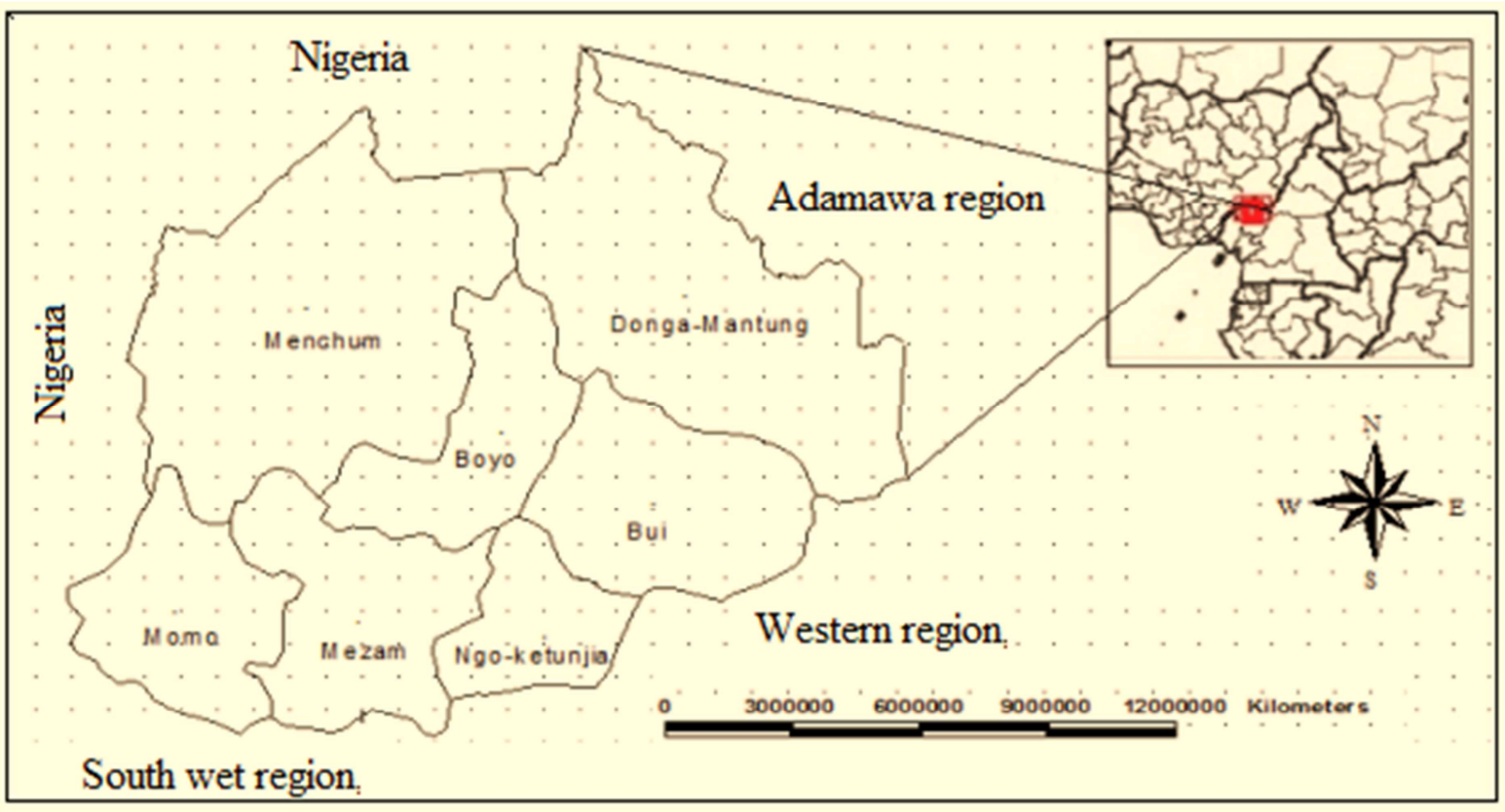

Figure 1. Location of the Bamenda Highlands region, Northwest Province, Cameroon.

Indigenous people retain strong links to and responsibility for the region, and they have a key role in protecting the cultural and natural heritage. The region supports a rich and diverse variety of plants and animals, is a centre of endemism, and despite its dry climate, has important rivers and wetlands. Peasant agriculture dominates the entire region. The main cash crop is tea. Cattle rearing and patches of apiculture and aquaculture also exist.

The region features several dormant volcanoes, including the Mount Oku of all. A cool temperate-like climate, influenced mainly by mountainous terrain and rugged topography also characterize the region. Annual temperature ranges between $15^{\circ}-32^{\circ} \mathrm{C}$, averaging about $23^{\circ} \mathrm{C}$, while average rainfall is about $2400 \mathrm{~mm}$ [24]. There are two main seasons; wet season (April - October), and dry season (November - February). Haplic Ferralsols in association with Rhodic Oxisols dominate the region. The region is also a challenging environment for agriculture due to high interannual variety in rainfall, temperatures and evapotranspiration, poor soil fertility, increasing human population, and the application of resource-depleting and polluting technology. Wind speed varies between 1.5 and 7.8 $\mathrm{Km} / \mathrm{hr}$ throughout the, and is highest during the growing season (Figure 2).

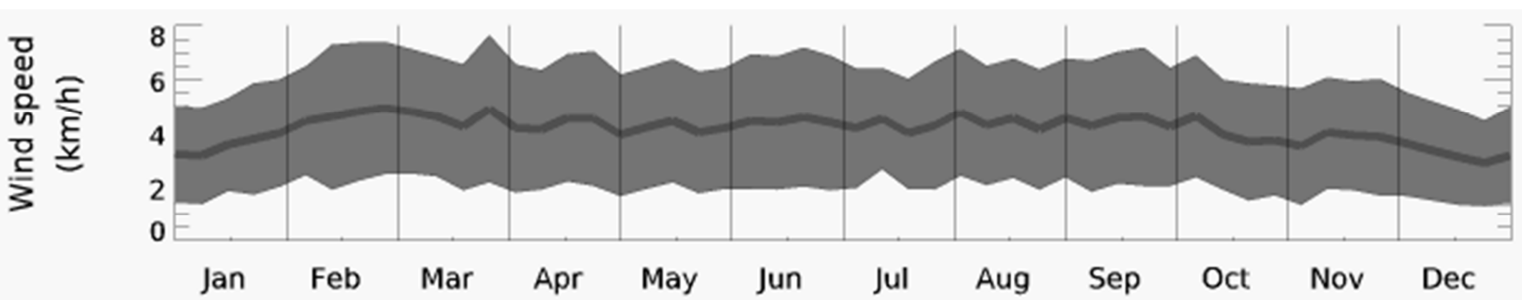

Figure 2. Variation in wind speed throughout the year in the region. 


\subsection{Study Population and Sampling Strategy}

The study solicited the participation of experts and stakeholders in three of the seven divisions that make up the region (Table 1).

Table 1. Sample points: climate stressors, societal impact and sample size.

\begin{tabular}{llll}
\hline Division & Climate-related stressor & Societal impact focus & Sample size \\
\hline Mezam & Drought and flood & Drinking water + Habitability+Crops+livestock + fish & 50 \\
Menchum & Drought and gas emissions & Drinking water + Habitability+Crops + livestock + fish \\
Ngoketunjia & Drought and flood & Drinking water + Habitability+Crops + livestock + fish \\
Total & & & 45 \\
\hline
\end{tabular}

Key participants were village regents, youth and women's group representatives. Smallholders were targeted because they manage over $80 \%$ of the world's estimated 500 million small farms and provide over $80 \%$ of the food consumed in a large part of the developing world [25]. The sites were selected to cover a wide range of ecosystems, geographic regions (mountains, plateaus) and climatic stressors (droughts, floods, gas emissions, changing rainfall patterns) as well as dependence of livelihoods on climate conditions (e.g., rainfed agriculture, fishing, herding).

\subsection{Data Collection}

Twenty-four year climatic data and crop yield statistic over the same period (1991 to 2015) were collected from secondary database in 2016 from government departments and organizational records. A combination of internet searches and peer reviewed journal articles complemented this database. Field visits, Focus Group Discussion (FGDs) and participatory social-ecological resilience assessment [26] using questionnaires constituted the source of our primary dataset. The FGDs began by asking the farmers to indicate crops they considered had the capability of resisting and adapting in an active way to dynamic changes in both sudden and long-term events. We discussed and scored some key indicators of social-ecological resilience: community assets, institutions, and agricultural practices in four main domains: (1) biodiversity, (2) knowledge and innovation (3) landscape diversity and ecosystem protection, and (4) livelihoods and wellbeing. The indicators were scored on a five-point scale, first by individual participants and then by the group as a whole through consensus, with higher scores indicating stronger elements of resilience. Respondents who perceived climate change were asked which of their crops they perceived to be tolerant and susceptible to the associated stresses based on recall data. Measuring community resilience is recognized as an essential step toward reducing disaster risk and being better prepared to withstand and adapt to a broad array of natural and human induced disasters [27].

\subsection{Data Analysis}

A mixed approach was adopted. Qualitative data obtained from group interviews field observations were transcribed into descriptive and reflective data that were suitable for converting into useful meaning of units following three procedures suggested by [28]. Quantitative data was coded and entered into SPSS 20.0 and both descriptive and inferential statistics were employed to understand how much of the dependent variables (crop species) are explained by the independent variables (temp, precipitation). Correlation analyses were used to examine the relationship between crop yields and the independent variables. Multiple regression model was used to understand how much of crop yield $\left(\mathrm{y}_{\mathrm{i}}\right)$ is explained by rainfall and temperature. The regression model used was of the form:

$$
y_{i}=\beta_{0}+\beta_{1} x_{1, i}+\cdots+\beta_{k} x_{k ; i}+\varepsilon_{i}
$$

which describes the relationship between a dependent variable, $\mathrm{y}_{\mathrm{i}}$, taking different values for each $i$ th observation, and a linear combination of independent variables, $\mathrm{x}_{1, \mathrm{i}} ; \ldots$, $\mathrm{x}_{\mathrm{k}, \mathrm{i}}$. The $\varepsilon_{\mathrm{i}}$ term represents the remaining error that cannot be explained by the model.

\section{Results and Discussions}

\subsection{Current and Future Trends in Climate Change}

The mean annual rainfall in the region was found to be $17.23\left( \pm .34^{\circ} \mathrm{C}\right)$ and temperatures in the region is increasing at the rate of about $.04^{\circ} \mathrm{C} \mathrm{y}^{-1}$ and is projected to attain $2^{\circ} \mathrm{C}$ rise in the next 50 years, everything being equal (Figure 3).

The model fits absolutely well (the forecast is off by $.009 \%$ ) and thus, can be used to predict the $\mathrm{Y}$ value for the next period in time. In a focus groups discussion, farmers expressed that they have never experienced heat like in recent years. Following [29] projection of possible temperature increase of between $3^{\circ} \mathrm{C}$ to $4^{\circ} \mathrm{C}$ in all four [African] regions and in all seasons, between the years 2080 to 2099 , it is safe to assume that temperature change across the Bamenda highlands will follow the general trend for the whole of Africa. Heat waves, floods and other impacts on ecosystems, human health and economy are likely to become more severe in the coming decades. 


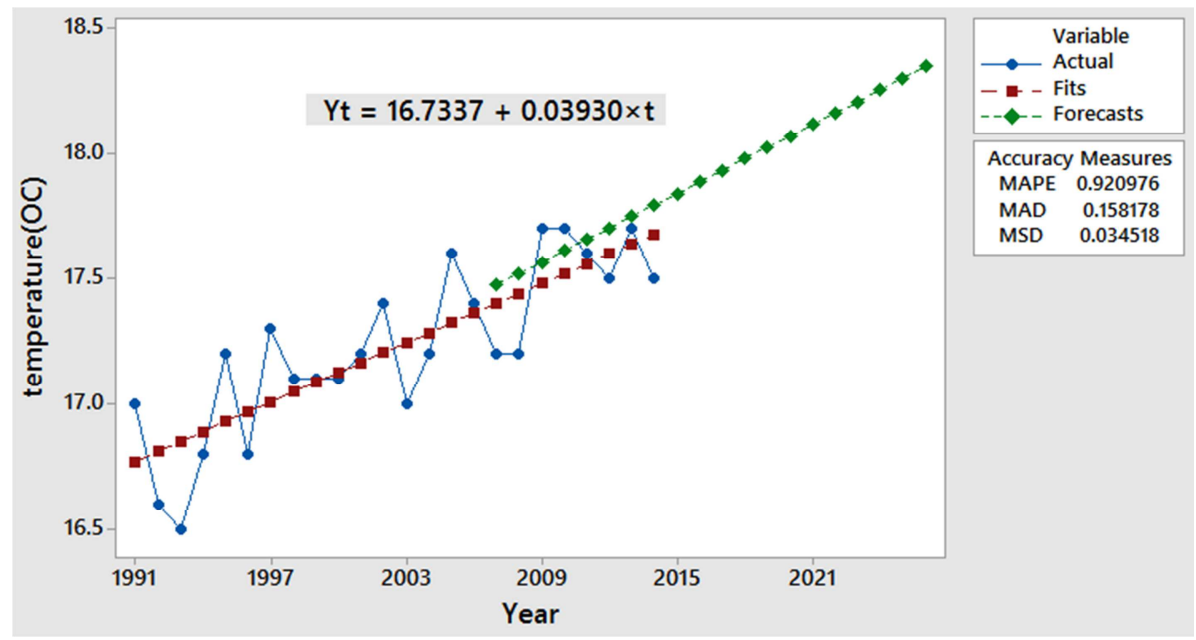

Figure 3. Trends in temperature over the past 24 years.

On the other hand, the mean annual rainfall for the region was $1969.05 \mathrm{~mm}( \pm 200.04)$. Average annual rainfall is expected to decrease drastically below $1200 \mathrm{~mm}$ per year, decreasing at a rate of about 7.04 per year (Figure 4).

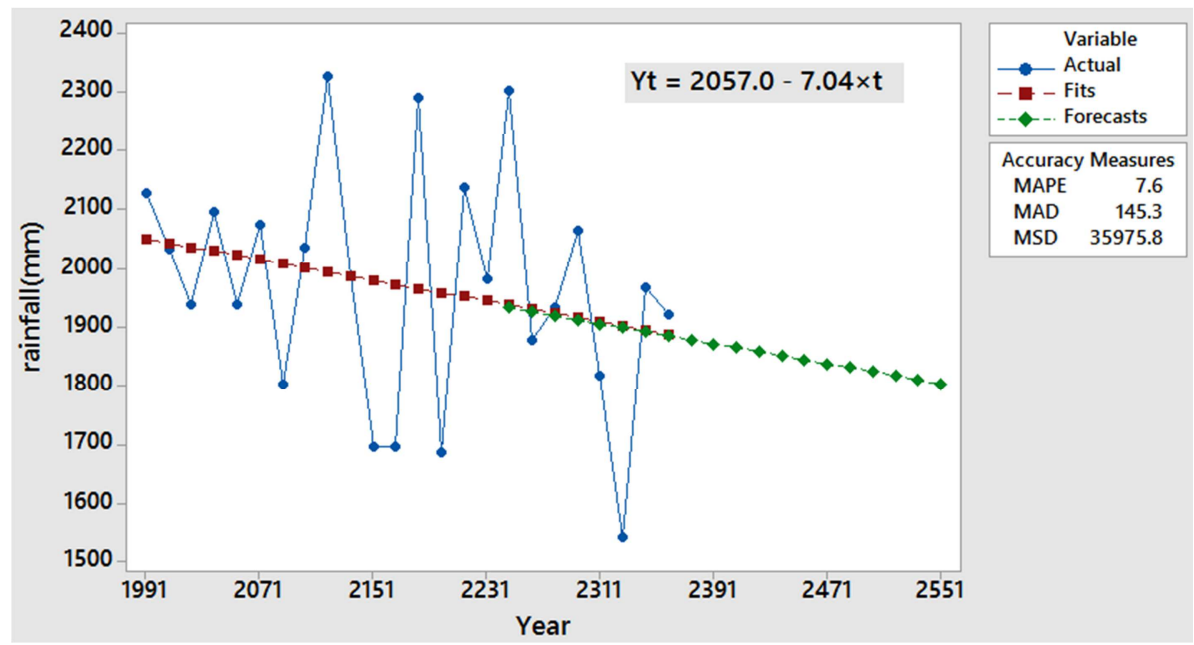

Figure 4. Trends in rainfall over the past 24 years.

The model fits absolutely well (the forecast is off by $.076 \%$ ). It suggests that the average annual rainfall in the next 24 years may decrease drastically below $1200 \mathrm{~mm}$. Changes in precipitation regimes include changes in seasonal mean, the timing and intensity of individual rainfall events, and the frequency and length of droughts. Decreasing rainfall over time has led to severe droughts in the region, decreasing stream flows for rivers in some areas, and increasing discharge others. Each of these factors is critical to crop productivity. However, there remains a degree of uncertainty in these predictions because of unresolved problems in estimating various positive and negative feedback mechanisms in air, earth, and ocean and vegetation interaction.

\subsection{Respondent's Perception on Climate Change and Variability}

Nevertheless, when the results were triangulated with individual perceptions, it was found that, of the 140 households surveyed, $94.27 \%$ perceived a change in climate conditions over the last 24 years. Of these, $82.03 \%$ observed an increase in temperature, and $87 \%$ observed a change in precipitation patterns. According to local farmers, rainfall has become more irregular with varying intensities. Rains at times come earlier than expected (early January to February), inducing farmers into errors of early planting. Over half of the farmers $(53.7 \%)$ explained climate variability as the extended dry season due to shifting rainfall. A third of the respondents $(33.3 \%)$ understood climate variability as decreases in rainfall while the remaining $13 \%$ defined climate variability as increase in temperature and rainfall change.

On the other hand, when respondents were asked about the causes of climate variability, most of them (77\%) mentioned deforestation, unplanned development, and uncontrolled degradation of water sources as the major factors of climate change. Other factors mentioned included overgrazing and bush fire $(21 \%)$. However, a smaller number of respondents (2\%) perceived climate change and variability as a result of breaking traditional rules laid down by their forefathers. They claimed that during their time, drought could be simply 
solved by a rain maker. Farmers perceptions to changes in temperature and rainfall variability are closely similar to empirical results from the analysis of rainfall and temperature trends as shown in the previous sections.

Respondents also reported increasing pest and disease pressure and soil degradation linked to the weather changes by 60.04 and $36 \%$ of respondents, respectively. The population sizes of pests have increased, and new species of pests and diseases have appeared. This supports [30] hypothesis that, with global warming, insects, whose body temperature varies with the temperature of the surrounding environment (poikilothermic) are most likely to move polewards and to higher elevations. The major pests and diseases include the yam anthracnose, sweet potato scab (Elsinoe batatas), taro beetle (Papuana spp), root fungus (Phytophtora), fruit piecing moth, fruit fly, and the giant African snail (Table 2).

Table 2. Bread crops that are vulnerable to climate change induced pests.

\begin{tabular}{llll}
\hline Crop (Local Names) & Scientific name & Indicators & Observed impact \\
\hline Taro Cocoyam & $\begin{array}{l}\text { Calocasia } \\
\text { esculenta }\end{array}$ & Attacked by fungi & $\begin{array}{l}\text { Leaves rot and the tuber decay completely in the soil. This crop is } \\
\text { threatened since 2010 }\end{array}$ \\
Ibo Cocoyam & Colocascia spp. & Attacked by fungi & Leaves rot and the tuber decay in the soil. going extinct since 2010 \\
Palm tree & Elaesis guineesis & Slow pollination on plant & Drop in productivity, increasing the cost per litre of palm oil. \\
Yam & Dioscorea spp. & Leaves dry up & Productivity dropped \\
Maize & Zea mays & Slow pollination, easily attacked by & Productivity is dropping, use of chemical fertilizers and pesticides \\
Pineapple & Ananoise sativa & Easily attacked by fungi & increasing \\
Beans & Vulgorus spp & Loss of leaves & Productivity drops \\
Sweet potatoes & Ipomea batatas & Loss of leaves & Drop in productivity \\
Irish potatoes & Solanum & Loss of leaves, easily attacked by & Drop in productivity \\
Plums & tuberosum & blight and other pests & Drop in productivity \\
\hline
\end{tabular}

\subsection{Trends in the Yields of Subsistence Crops}

The rains will abruptly give way to intense dry periods often characterised by extreme heat, causing damages to crops, leading to a general decline in crop yields of some

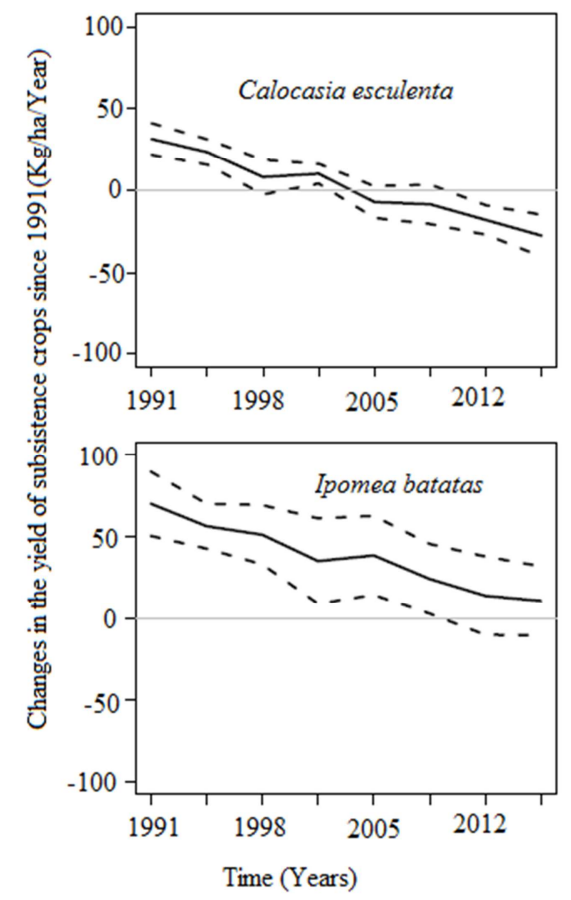

staple food crops in the region such as the maize (Zea mays), cocoyams (Calocasia esculenta), yams (Dioscorea spp.) and potatoes (Ipomea batatas, and Solanum tuberosum) in the early years (Figure 5), and are still decreasing.
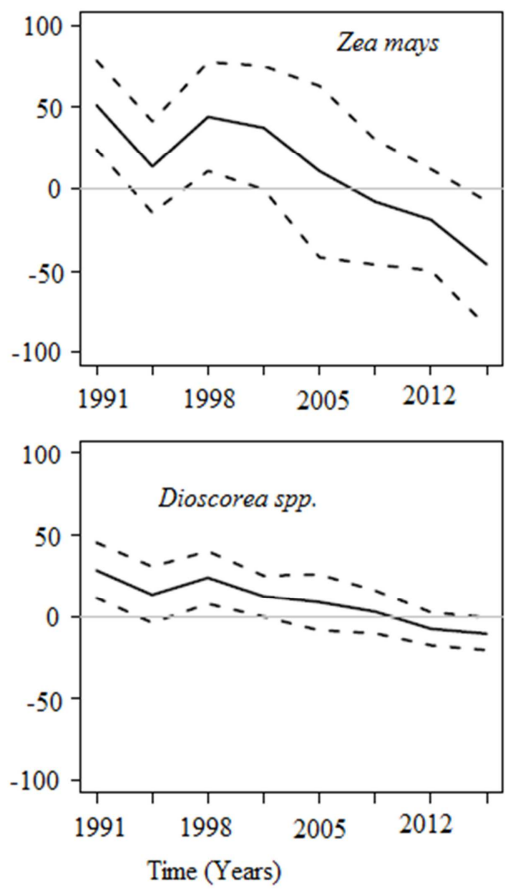

Figure 5. Estimated yield trends of selected subsistence crops in the region from $1991-2016$ based on field data. The solid line shows the mean estimate on yield trends while the dotted lines indicate 95\% confidence interval. A 95\% confidence interval is a range of values that you can be $95 \%$ certain contains the true mean of the population.

To further investigate if climate change parameters (rainfall and temperature) do indeed explain the results obtained in figure 3 , basic statistical analysis was carried out. On the whole, the main effect of temperature was significant, $F(2,23)$
$=7.91, M S E=23.20, p<.01$, as was the main effect of precipitation, $F(2,23)=12.70, M S E=23.20, p<.01$. The interaction of these two factors was not significant, $F(2,23)=$ 2.71, $M S E=23.20, n$. s. The results suggest that the yield 
trends could be explained by the climate change parameters.

Declining yields have led to high prices of food items in the market, and these prices are still increasing. Food security is potentially undermined where food price increases following harvest loss whether in regions neighboring or distant disproportionately affect the urban poor [31-32]. Between 2013 and 2017, 52\% of households in the region said they had experienced food insecurity at least once in the past 12 months, with the incident highest among couples with children compared with all other types of families. The situation seems to be aggravated by the current worsening socio-political situation (Anglophone crises) in the region, and is expected to increase especially with increase in deforestation, ecologically unfriendly agricultural practices, increase in corrupt practices, and limited access to capital and technology.

The results also suggest a decline in crop diversity. Such decline may have implications for the resilience of farm systems in the region, which is amplifying existing stresses and making the environment more unpredictable. Unfortunately, the decline fails to leverage with increase in the amount of agricultural inputs thus increasing hunger and poverty. Similar studies have reported that, with a $1^{\circ} \mathrm{C}$ increase in average temperatures, yields of the major food crop species can decrease by 5 to 10 percent [33]. With higher average temperatures plants also complete their growing cycle more rapidly [34]. With less time to reproduce, reproductive failures are more likely and this will also lower yields [35]. However, agricultural diversification emerged as a promising strategy for climate resilience more broadly and highlights the need for future research to assess the potential of diversified agroecosystems to buffer climate effects on crop quality. Numerous previous studies have highlighted that agricultural diversification strategies are crucial for resilience [36]. Different species or genotypes within an agroecosystem may perform different functions [37] and have different physiological thresholds in response to climate variability [38] and thus enhance the resilience of an ecosystem [39].

\subsection{Trends in the Yields of Cash Crops}

Formerly, tea production was the sole responsibility of the Ndu estate. Today is the Ndawara tea estate. Following data collected from the former, cash crops seem to be more tolerant to climate (Figures $6 \& 7$ ).

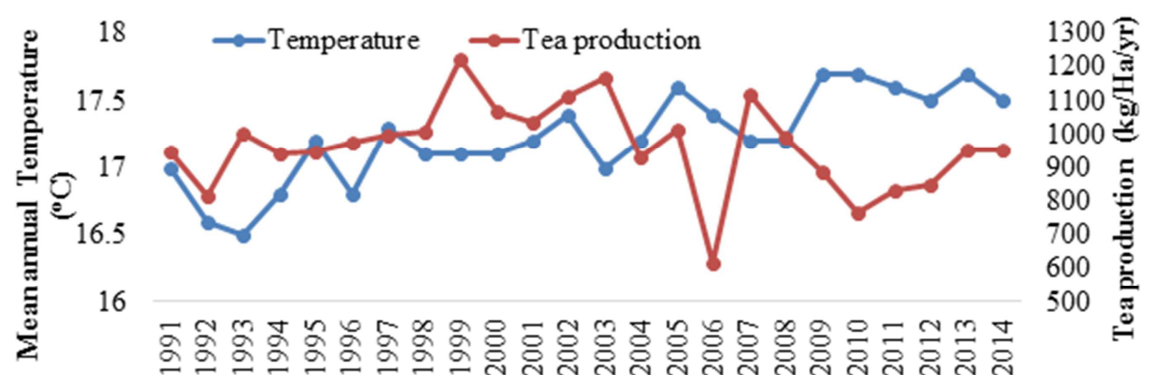

Time (Years)

Figure 6. Relationship between annual temperature and tea yield.

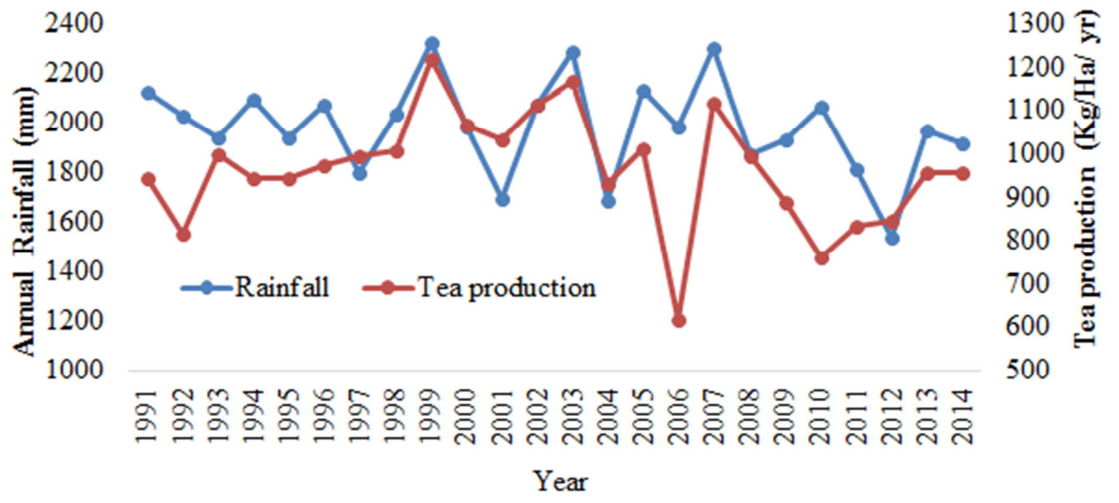

Figure 7. Relationship between tea yield and rainfall.

On the whole, we found that, for the lone cash crop, tea, there was a weak positive correlation between rainfall and yield $(r(24)=.323, p=0.124)$, and a weak negative correlation between yield and temperature $(r(24)=-0.324, p$ $=.122$ ). This indicates that coffee production may not much be influenced by both temperature and rainfall variability. The two predictors explained $16.4 \%$ of the variance $\left(R^{2}=.164\right.$, $F(2,21)=2.065, p=.152)$. Neither rainfall $(\beta=.296, p$
$=.236)$ nor temperature $(\beta=.-177.013, p=.233)$ significantly predicted coffee yield. The regression model further suggests an expected yield of $3393.67 \mathrm{Kg} / \mathrm{ha} /$ year of tea, rainfall and temperature being constant. On the other hand, a unit increase in temperature is expected to reduce production by $177 \mathrm{Kg} / \mathrm{ha} /$ year, while a unit change in rainfall could raise production by $.269 \mathrm{Kg} / \mathrm{ha} /$ year. The reduction in seasonal mean precipitation could have greater impact on 
areas with degraded soils. It should be recalled that the soils in the region are dominated by laterite with low levels of organic carbon resulting from age long sheet and gulley erosions, and therefore retain less water at low moisture potentials. Crops grown on such nutrient-poor soils (potassium deficient), recover less quickly from drought stress once water is again available.

Seventy percent of the respondents attributed the decreasing yields to non-climatic factors. Of this $70 \%, 74 \%$ complaint of poor motivation factors, while the remaining $26 \%$ attributed it to other factors like shortage of agricultural inputs (fertilizers and pesticides) which influence coffee production. The findings of this study are consistent with those of [40], who reported devastated production of coffee in Colombia and Central America due to a combination of factors, including changing climatic conditions. strategies such as agro-forestry, crop rotations, mixed cropping, landscape mosaics, polycultures, and maintenance of diverse landraces. For example, surveys with tea farmers in southern Yunnan of China indicate that tea agro-forests are more resilient to climate variability compared to monoculture terrace tea gardens [41].

\subsection{Perceptions of Crops' Tolerance to Climate Change Related Stresses}

Some crops are more tolerant than others to certain types of stresses, and at each phenological stage, different types of stresses affect each crop species in different ways. Sixty eight percent $(68.07 \%)$ of respondents in the survey reported suffering yield declines over time. as a result of changing climate. They cited some local crops and varieties were identified as key assets for adaptation because of their stress tolerance, however, others may be vulnerable (Figure 8) to the rapidly changing agroecological conditions

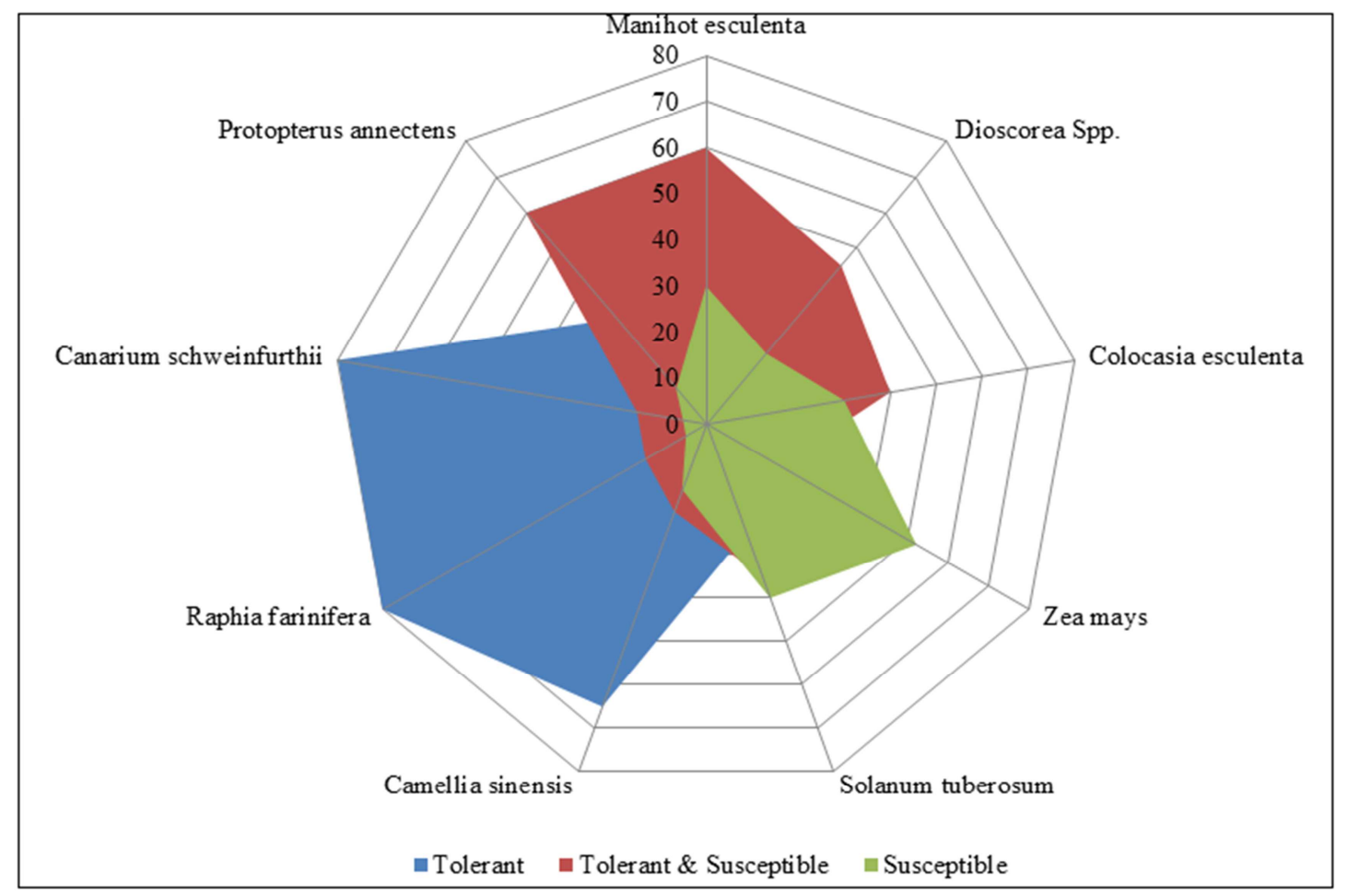

Figure 8. Farmers' perceptions of crop tolerance to climate change stresses in the region.

Most crops can tolerate higher daytime temperatures during vegetative growth, with photosynthesis reaching an optimum at between $20^{\circ} \mathrm{C}$ and $30^{\circ} \mathrm{C}$ [42]. During the reproductive stage, yields decline when daytime high temperatures exceed $30^{\circ} \mathrm{C}$ to $34^{\circ} \mathrm{C}$ [43]. Extremely high temperatures above $30^{\circ} \mathrm{C}$ can do permanent physical damage to plants and, when they exceed $37^{\circ} \mathrm{C}$, can even damage seeds during storage.

\subsection{Participatory Social-ecological Resilience Assessment}

The findings emphasise the importance of a number of dimensions, including health and well-being (24.5\%), governance (18\%), physical and environmental (17.4\%), economic (15.9\%), information and communication (14.3\%) and social $(9.9 \%)$. Consensus scores and trends for ten indicators of social-ecological resilience for all the indicators in four domains generally ranged from low to medium (Table 3 ), indicating a rather weak capacity of groups or communities to cope with external stresses and disturbances as a result of social, political and environmental change, and of ecosystems to maintain themselves in the face of disturbances. 
Table 3. Results of the community resilience self-assessment.

\begin{tabular}{|c|c|c|c|}
\hline Domain & Indicator & Consensus score $\&$ trend & Explanation for scores \& trends \\
\hline $\begin{array}{l}\text { Landscape } \\
\text { diversity \& } \\
\text { ecosystem } \\
\text { protection }\end{array}$ & $\begin{array}{l}\text { Landscape diversity } \\
\text { Ecosystem protection } \\
\text { Landscape integration } \\
\text { Recovery \& regeneration of } \\
\text { the landscape }\end{array}$ & $\begin{array}{l}\text { Moderate }(2 / 5) \text { Decreasing } \\
\text { Low }(1 / 5) \text { Decreasing Low } \\
(1 / 5) \text { Increasing Moderate } \\
\text { (2/5) Slight change }\end{array}$ & $\begin{array}{l}\text { Trees, farms around houses in the landscape and fewer now than in the past. } \\
\text { Knowledge of planting does less than } 50 \text { years ago Few protected areas but not } \\
\text { sustained General decline in production services of ecosystems. Adoption of } \\
\text { organic inputs in agriculture on the rise. Extreme temperatures \& interannual } \\
\text { variations in rainfall retard crop growth, extinction of and loss of biodiversity. }\end{array}$ \\
\hline Biodiversity & $\begin{array}{l}\text { Crop/animal diversity } \\
\text { Local food diversity }\end{array}$ & $\begin{array}{l}\text { Low }(1 / 5) \text { Decreasing } \\
\text { Moderate }(2 / 5) \text { Decreasing }\end{array}$ & $\begin{array}{l}\text { Most animal/plant species are rare. Become available in small populations as } \\
\text { one moves away from urban to most rural landscapes. Adoption of improved } \\
\text { seed varieties but knowledge is yet to be diversified. }\end{array}$ \\
\hline $\begin{array}{l}\text { Knowledge } \\
\& \\
\text { innovation }\end{array}$ & $\begin{array}{l}\text { Innovative practices } \\
\text { Traditional knowledge } \\
\text { related to biodiversity }\end{array}$ & $\begin{array}{l}\text { Medium (3/5) Decreasing } \\
\text { Moderate }(2 / 5) \text { Decreasing }\end{array}$ & $\begin{array}{l}\text { The community is working with NGOs (e.g. SHUMAS) to improve } \\
\text { productivity mainly though organic soil inputs. They are also trying to add } \\
\text { value to their products. Decreases from rural to urban areas \& in hands of } \\
\text { elderly. Fear of traditional knowledge loss as it is not documented and young } \\
\text { people are leaving. }\end{array}$ \\
\hline $\begin{array}{l}\text { Livelihoods } \\
\text { \& wellbeing }\end{array}$ & $\begin{array}{l}\text { Income diversity } \\
\text { Biodiversity-based } \\
\text { livelihoods }\end{array}$ & $\begin{array}{l}\text { Medium (3/5) No change } \\
\text { Medium (3/5) Increasing }\end{array}$ & $\begin{array}{l}\text { Some off-farm works Younger people are not interested in biodiversity-based } \\
\text { livelihoods, though livelihoods in some forest communities have improved } \\
\text { with the help of some development NGOs. }\end{array}$ \\
\hline
\end{tabular}

Previous research demonstrates that the extent and application of social capital is a crucial element in determining the nature of resilience at the community level [44]. However, there is growing evidence that, if land degradation can be both reduced now and avoided in future and the health of degraded land is restored, communities everywhere will thrive. They will have access to clean water, and produce more crops that can create reliable, paying jobs in rural areas. Food harvests will increase where hunger persists. Considering that climate change is overlaying and interacting with other non-climatic factors affecting agriculture, it follows that taking the impacts of climate change as a starting point of analysis has serious limitations.

\section{Conclusion}

This paper is intended to inform the policies and practices of donors, implementing partners, NGOs, government and other stakeholders by establishing conceptual and measurement frameworks for community resilience. Climate change is bringing ever greater uncertainty and exposure to multiple climate stresses in the Bamenda Highlands of Cameroon. Drought, flood, and pest and disease outbreaks are becoming increasingly frequent and unpredictable within and between years. Few crops and varieties were perceived as tolerant to all these major stresses, which explains why farmers continue to maintain several varieties at the household level with different tolerance traits. By identifying the specific elements of community resilience and the ways in which they interact, the paper clarifies the types of information that must be collected in order to adequately measure it. The concept of community resilience presented here focuses on collective or communal access to and use of livelihood assets. As such, the paper asserts that community capacity for collective action to manage shocks and stresses is a key attribute distinguishing community resilience from resilience at the household level.

The results of this study provide some fascinating insights into the cognitive and physiological effects of climate change. In line with other studies, agrobiodiversity is under threat of climatic stressors. The involvement of the community provided local context of the issues and local knowledge about potential solutions, which is a foundation for relevant and realistically implementable scenarios. Agricultural genetic resources are not only a victim of climate change; they are of fundamental importance for adaptation to this change and are crucial to coping with the problems it poses.

We recommend a strategic framework for climate risk mitigation in the region. An agrobiodiversity strategy needs to take account policy makers and stakeholders at all levels across the grassland area in the development and implementation of coherent and effective policies and measures by identifying strategic objectives, strategic directions and priorities that promote the right enabling environment for mainstreaming adaptation in national and local planning, promote and exchange best practices and low-regret measures; promote leveraging of necessary funding, and exchange and access best available data, knowledge, assessments and tools on adaptation. Joining efforts to build community resilience, specifically by increasing livelihood diversity, local ecological knowledge, and social network connectivity, may help conservation agencies conserve the rapidly declining biodiversity in the region.

\section{Acknowledgements}

The authors gratefully acknowledge His Excellency Paul Biya, President of Cameroon, for the special modernization allowance granted to University lecturers.

\section{References}

[1] Aggarwal PK, Kalra N, Chander S, et al. InfoCrop: A dynamic simulation model for the assessment of crop yields, losses due to pests, and environmental impact of agro-ecosystems in tropical environments. I. Model description. Agric Syst 2006; 89: 1-25. 6.

[2] Ahmed, S. A., Diffenbaugh, N. S., Hertel, T. W., 2009a. Climate volatility deepens poverty vulnerability in developing countries. Environ. Res. Lett. 4, 034004. 
[3] Aldrich, D. P. (2012a), Building Resilience: Social Capital in Post-Disaster Recovery. Chicago: University of Chicago Press.

[4] Aydogdu, M. H. and Yenigün, K. 2016. Farmers' Risk Perception towards Climate Change: A Case of the GAP-Şanlıurfa Region, Turkey. Sustainability, 8 (8): 806.

[5] Avelino J, Cristiancho M, Georgiu S, Imbach P, Aguilar L, Bornemann G, Laderach P, Anzueto F, Hruska AJ, Morales C. 2015. The coffee rust crises in Colombia and Central America (2008-2013): impacts, plausible causes and proposed solutions. Food Sec 7 (2): 3030-3321. doi: 10.1007/s12571-015-0446-9

[6] Barrett, C. and P. Santos (2014). The impact of changing rainfall variability on resource-dependent wealth dynamics. Ecological Economics 105, 48-54.

[7] Bassu, S., N. Brisson, J.-L. Durand, K. et al. 2014: How do various maize crop models vary in their responses to climate change factors? Glob. Change Biol., 20, no. 7, 2301-2320, doi: 10.1111/gcb.12520.

[8] Binder CR, Hinkel J, Bots PWG, Pahl-Wostl C (2013) Comparison of framework for analyzing socio-ecological systems. Ecol Soc 18 (4): 26.

[9] Bell J, Taylor M. 2015. Building climate-resilient food systems for Pacific Islands. Program Report: 2015-15. WorldFish, Penang, Malaysia.

[10] Bhagwat SA, Willis KJ, Birks HJB, Whittaker RJ. 2008. Agroforestry: A refuge for tropical biodiversity? Trends in Ecology \& Evolution 23: 261-267.

[11] Bergamini N, et al. 2014. Toolkit for the indicators of resilience in socioecological production landscapes and seascapes. Policy report. UN University Institute for the Advanced Study of Sustainability, Tokyo, Biodiversity International, Rome, Institute for Global Environmental Strategies, Japan, and the UN Development Programme, New York.

[12] Burton, C. G., 2014. A validation of metrics for community resilience to naturalhazards and disasters using the recovery from Hurricane Katrina as a casestudy. Ann. Assoc. Am. Geogr. 105, 67-86.

[13] Chelleri, L.; Olazabal, M. 2012. Multidisciplinary Perspectives on Urban Resilience; Basque Centre for Climate Change: Bilbao, Spain.

[14] Constas, M. A. \& Barrett, C. (2013). Principles of resilience measurement for food insecurity: Metrics, mechanisms, and implementation plans. Paper presented at the Expert Consultation on Resilience Measurement Related to Food Security, sponsored by the Food and Agricultural Organization and World Food Program, Rome, Italy, February 19-21, 2013.

[15] Craufurd, P. Q., and Wheeler, T. R. (2009). Climate change and the flowering time of annual crops. J. Exp. Bot. 60, 2529-2539.

[16] Durand, J. L., K. Delusca, K. Boote, J. Lizaso, R. Manderscheid, H. J. Weigel, A. C. Ruane, C. Rosenzweig, J. Jones, and L. Ahuja, 2018: How accurately do maize crop models simulate the interactions of atmospheric $\mathrm{CO} 2$ concentration levels with limited water supply on water use and yield? Eur. J. Agron., 100, 67-75.

[17] FAO, IFAD and WFP. 2015. The State of Food Insecurity in the World 2015. Meeting the 2015 international hunger targets: taking stock of uneven progress. Rome, FAO FAO (Food and Agriculture Organization). 2010. Building resilience to climate change: root crop and fishery production. Pacific Food Security Toolkit. Food and Agriculture Organization, Rome.

[18] FAO. 2016b. Climate change and food security. Risks and responses. Italy.

[19] FAO. 1999a. Agricultural Biodiversity, Multifunctional Character of Agriculture and Land Conference, Background Paper 1. Maastricht, Netherlands. September 1999.

[20] Feola, G. 2014. Narratives of grassroots innovations: a comparison of Voluntary Simplicity and the Transition Movement in Italy. International Journal of Innovation and Sustainable Development 8 (3): 250-269.

[21] Hatfield J. L., Boote K. J., Kimball B. A., Ziska L. H., Izaurralde R. C., Ort D., et al. (2011). Climate impacts on agriculture: implications for crop production. Agron. J. 103351-370. 10.2134/agronj2010.0303.

[22] Hertel TW, Burke MB, Lobell DB (2010) The poverty implications of climate-induced crop yield changes by 2030 . Glob Environ Change 20 (4): 577-585.

[23] Holling, C. S. Resilience and stability of ecological systems. Annu. Rev. Ecol. Evolut. Syst. 1973, 4, 1-23.

[24] IPCC. 2007a. Climate Change 2007: The Physical Science Basis. Contribution of Working Group I to the Fourth Assessment Report of the IPCC. In S. Solomon, D. Qin, M. Manning, Z. Chen, M. Marquis, K. B. Averyt, M. Tignor and H. L. Miller, eds. Cambridge, UK: Cambridge University Press. 996 pp.

[25] Jacobi J, Schneider M, Bottazzi P, Pillco M, Calizaya P, et al. 2015. Agroecosystem resilience and farmers' perceptions of climate change impacts on cocoa farms in Alto Beni, Bolivia. Renewable Agriculture and Food Systems 30: 170-183.

[26] Jiggins, J., \& Rölling, R. 2000. Adaptive management: Potential and limitations for ecological governance. International Journal of Agricultural Resources, Governance, and Ecology, 1 (1), 28e42.

[27] Kumar, A., Sharma, P. and Joshi, S. 2016. Assessing the Impacts of Climate Change on Land Productivity in Indian Crop Agriculture: An Evidence from Panel Data Analysis. J. Agric. Scie. Technol., 18 (1): 1-13.

[28] Lin B. B., 2007. Agroforestry management as an adaptive strategy against potential microclimate extremes in coffee agriculture. Agr Forest Meteorol 144: 85-94.

[29] Iizumi, T. et al. 2014a. Impacts of El Nino Southern Oscillation on the global yields of major crops, Nature Communications, 5: 3712 .

[30] Lobell, D. B., Schlenker, W., Costa-Roberts, J., 2011. Climatetrendsandglobalcrop production since1980. Science333, 616-620.

[31] Lobell, D. B., M. B. Burke, C. Tebaldi, M. D. Mastrandrea, W. P. Falcon, and R. L. Naylor, 2008: Prioritizing climate change adaptation needs for food security in 2030. Science, 319, 607610 .

[32] Miles, M. B., \& Huberman, A. M. (1994). Qualitative Data Analysis: An Expanded Sourcebook. Thousand Oaks, CA: Sage Publications. 
[33] Ndoh M. I., Jiwen G. 2008. Towards a sustainable land use option in the Bamenda Highlands, Cameroon: Implication for Climate Change Mitigation, Income Generation and Sustainable Food supply. Research Journal of Applied Sciences, 3 (1): 51-65.

[34] Nguyen Q, Hoang MH, Oborn I, van Noordwijk M. 2013. Multipurpose agroforestry as a climate change resiliency option for farmers: an example of local adaptation in Vietnam. Climatic Change 117: 241-257.

[35] O'Brien, G., P. O'Keefe, J. Rose, and B. Wisner. 2006 Climate change and disaster management. Disasters 30 (1): 64-80.

[36] Pishbahar, E. and Darparnian, S. 2016. Factors Creating Systematic Risk for Rainfed Wheat Production in Iran, Using Spatial Econometric Approach. J. Agr. Sci. Tech., 18 (4): 895-909.

[37] Quazi SA, Ticktin T. 2016. Understanding drivers of forest diversity and structure in managed landscapes: secondary forests, plantations, and agroforests in Bangladesh. Forest Ecology and Management 366: 118-134.

[38] Serre, D.; Barroca, B.; Laganier, R. Resilience and Urban Risk Management; CRC Press: Boca Raton, FL, USA, 2012.
[39] Trenberth, K. E., et al. (2007), Observations: Surface and atmospheric climate change, in Climate Change 2007: The Physical Science Basis, Contribution of Working Group I to the Fourth Assessment Report of the Intergovernmental Panel on Climate Change, edited by S. Solomon et al., pp. 235-336, Cambridge Univ. Press, New York.

[40] UNCCD. White Paper 1: Economic and Social Impacts of Desertification, Land Degradation and Drought. 2nd UNCCD Scientific Conference, 9-12 April 2013.

[41] Vandermeer J, van Noordwijk M, Anderson J, Ong C, Perfecto I. 1998. Global change and multi-species agroecosystems: Concepts and issues. Agr Ecosyst Environ 67: $1-22$.

[42] Wahid, A., Close, T. J., 2007. Expression of dehydrins under heat stress and their relationship with water relations of sugarcane leaves. Biol. Plant. 51, 104-109.

[43] Worldbank (2011): Policy Brief: Opportunities and Challenges for Climate-Smart Agriculture in Africa.

[44] Yachi S, Loreau M. 1999. Biodiversity and ecosystem productivity in a fluctuating environment: The insurance hypothesis. P Natl A. 